\title{
KEANEKARAGAMAN ORDO ANURA DIKEBUN KOPI DESA KARANG REJO KABUPATEN BENER MERIAH
}

\author{
Dilla Farhana ${ }^{1}$, Husnul Muna Bella ${ }^{2}$, Yayi Retno Pangestu Wijaya ${ }^{3}$, Fadillah Natasya ${ }^{4}$ \\ Prodi Pendidikan Biologi Fakultas Keguruan Dan Ilmu Pendidikan \\ Universitas Samudra \\ Email : dillafarhana6@gmail.com
}

\begin{abstract}
ABSTRAK
Desa Karang Rejo memiliki ekosistem pegunungan teropis, yang terletak di kabupaten Bener Meriah. Beberapa kawasan Didesa Karang Rejo adalah perkebunan kopi milik masyarakat sekitar, terdapat beberapa jenis spesies katak di kebun kopi namun belum ada data mengenai keanekaragaman katak di kebun kopi tersebut, padahal katak sangat berperan dalam ekosistem tersebut. Salah satu komponen ekosistem yang memiliki peranan yang sangat penting bagi kelangsungan proses ekologi yaitu ordo anura karena hewan amfibi terutama pada tahap telur dan berudu sangat sensitif terhadap kerusakan lingkungan. Tujuan penelitian ini adalah untuk mengetahui keanekaragaman jenis kata di kebun kopi desa Karang Rejo Kbupaten Bener meriah. Penelitian ini dilaksanakan di Desa Karang Rejo Kabupaten Bener Meriah, pada tanggal 10-15 juni 2021. Jenis penelitian yang digunakan adalah penelitian deskriptif dengan metode perjumpaan visual (visual Encounter survey). Hasil peneliian menunjukan terdapat 4 spesies dari 3 jenis spesies diantaranya spesies kodok kalong (Bufo melanostictus) dari Family Bufonidae dengan ciri-ciri tubuh sedikit bulat, kodok sawah (Fejervary cancrivora) dari family Ranidae dengan ciri khusus memiliki punggung berarna coklat licin, katak pohon (Polypedates leucomystax) dari family Rhacophoridae memiliki khas berpostur tubuh ramping kemudian kongkang siberut Pulchranacentropeninsularis) dan katak spesies terakhir Katak panggul (Limnonectes blythii) . Keanekaragaman Amfibi Ordo Anura yang terdapat di kebun kopi, Desa Karang Rejo Kabupaten Bener Meriah adalah rendah yaitu 0,4207
\end{abstract}

Kata Kunci : Keanekaragaman, Ordo Anura, Kebun kopi

\section{ABSTRACT}

Karang Rejo Village has a tropical mountain ecosystem, which is located in Bener Meriah district. Some areas in Karang Rejo Village are coffee plantations belonging to the surrounding community, there are several types of frog species in the coffee garden but there is no data on the diversity of frogs in the coffee garden, even though frogs play a very important role in the ecosystem One of the ecosystem components that has a very important role for the continuity of ecological processes is the order anura because amphibians, especially at the egg stage and tadpoles, are very sensitive to environmental damage. The purpose of this study was to determine the diversity of word types in the coffee garden of Karang Rejo village, Bener Meriah Regency. This research was conducted in Karang Rejo Village, Bener Meriah Regency, on 10-15 June 2021. The type of research used was descriptive research with the visual encounter survey method (visual Encounter survey). The results of the study showed that there were 4 species of 3 types of species including the bat frog species (Bufo melanostictus) from the Bufonidae family with slightly rounded body characteristics, the rice field frog (Fejervary cancrivora) from the Ranidae family with the special feature of having a smooth brown back and the last frog. tree (Polypedates leucomystax) from the family Rhacophoridae has a distinctive slender body posture. The diversity of amphibians of the Order Anura found in coffee plantations, Karang Rejo Village, Bener Meriah Regency is low at 0,4207 


\section{PENDAHULUAN}

Desa Karang Rejo adalah salah satu desa yang terletak di Kabupaten Bener Meriah yang memiliki ekosistem pegunungan tropis. Beberapa kawasan yang terletak di desa Karang Rejo sebagian adalah perkebunan kopi. Berdasarkan hasil observasi yang dilakukan terdapat beberapa jenis Katak yang terdapat diperkebunan kopi desa Karang Rejo. Katak dan Kodok adalah nama umum yang termasuk kedalam kelompok hewan amfibi dan secara taksonomi masuk kedalam kelas Amphibia dan ordo Anura serta tergolong kedalam Herpetofauna (Zug dkk.,2001; Vitt \& Caldwell,2014).

Amfibi yang tergolong kedalam Herpetofauna yang merupakan salah satu potensi keanekaragaman fauna dan jarang diketahui serta kurang dikenal oleh masyarakat. Pemahaman keanekaragaman fauna di suatu kawasan adalah penting, karena masing-masing fauna termasuk herpetofauna yang memiliki peran dalam menjaga keseimbangan dan keberlangsungan ekosistem kawasan tersebut (Eprilurahman et al., 2009). Pengendali hama (jenis-jenis pemakan tikus dan juga serangga) dan sebagai sumber plasma nutfah merupakan salah satu peranan herpetofauna yang terjadi di alam khususnya dikawasan pertanian. Herpetofauna juga merupakan kelompok hewan yang memiliki jenis beragam dan dengan bentuk yang menarik (Irwanto et al., 2019).

Beberapa penelitian mengenai herpetofauna yang dilakukan beberapa tahun terakhir menunjukkan adanya penurunan populasi secara global yang dimulai pada tahun 1980-an seiring dengan adanya peningkatan pencemaran lingkungan dan berkurangnya habitat asli mereka

(Subeno, 2018). Terjadinya penurunan kualitas pada ekosistem tersebut menandakan menurunnya atau hilangnya populasi herpetofauna pada habitat aslinya. Terdapat beberapa jenis herpetofauna yang memiliki habitat spesifik sehingga sangat berguna sebagai indikasi atau peringatan dini akan terjadinya perubahan kualitas lingkungan (Sardiet al., 2014).

Salah satu komponen ekosistem yang memiliki peranan yang sangat penting bagi kelangsungan proses ekologi yaitu ordo anura karena hewan amfibi terutama pada tahap telur dan berudu sangat sensitif terhadap kerusakan lingkungan (Kusrini, 2013). Spesies adalah sekelompok individu yang menunjukkan beberapa karakteristik penting yang berbeda dari kelompok-kelompok lain, baik secara morfologi, habitat, atau biokimia (Dharma, et al. 2019)

Anura merupakan salah satu ordo yang terdapat pada kelas amfibia; yaitu spesies amfibia yang tidak memiliki ekor. Anura ordo yang paling umum dijumpai dan dikenal dengan nama katak dan kodok. Maksud spesies Anura dalam penelitian ini adalah spesies Anura yang 364 
terdapat di Kawasan kebun kopi desa Karang Rejo Kabupaten Bener Meriah. Menurut Mistar Kamsi (2003) yang menyatakan bahwa ordo (Bangsa) Anura adalah kelompok amfibia yang tidak memiliki ekor, dan dikenal dengan nama katak dan kodok. Spesies ini paling umum dijumpai di Indonesia, Di pulau Sumatera sedikitnya tercatat 110 Spesies, 6 famili yaitu; Bufonidae, Dicroglossidae, Megophryidae, Microhylidae, Ranidae, dan Rhacophoridae.

Data mengenai keanekaragaman Anura di kawasan kebun kopi ini masih belum tersedia, kondisi data yang tidak tersedia tersebut menjadikan pentingnya penelitian tentang keanekaragaman Anura di kawasan ini.Tujuan penelitian ini untuk mengidentifikasi dan menganalisis keanekaragaman ordo anura pada habitat kebun kopi. Penelitian ini diharapkan dapat memberikan manfaat berupa informasi yang jelas tentang keberadaan jenis-jenis dan jumlah individu Anura yang terdapat di kebun kopi, Desa Karang Rejo, Kabupaten Bener Meriah, yang dapat digunakan dalam acuan sebagai pelestarian dan perlindungan amfibi di masa depan.

\section{METODELOGI PENELITIAN}

\section{Waktu Dan Tempat}

Penelitian ini dilaksanakan pada tanggal 10 - 15 Juni 2021 di kebun kopi, Desa Karang
Rejo, Kabupaten Bener Meriah.

\section{Metode Dan Variabel}

Jenis penelitian yang digunakan dalam penelitian ini ialah penelitian deskriptif dengan metode perjumpaan visual (Visual Encounter Survey) (Heyer et al, 1994).

Jumlah jalur yang dibuat hanya 1 jalur yang mengikuti kawasan kebun kopi seluas 1 hektar. Pencarian jenis katak dilakukan dengan cara berjalan mengitari lokasi yang telah ditentukan pada pagi dan siang hari. Pagi hari pada pukul 06.00 - 10.00 WIB. Dan pada sore hari dimulai dari pukul 17.00 - .19.30 WIB. Semua katak yang terlihat akan langsung diambil/ditangkap menggunakan jaring.

Alat yang digunakan dalam penelitian ini ialah jaring, sepatu boot, sarung tangan, tali raffia, alat tulis, kamera.

Adapun data Ordo Anura yang telah ditangkap dianalisis dengan rumus sebagai berikut:

\section{Indeks Keanekaragaman}

$$
\left(\mathrm{H}^{\prime}\right)=-\sum_{t=l}^{s} p i \ln p i
$$

Keterangan:

$$
\text { H' = Indeks keanekagaraman Shannon-Wiener }
$$

$\mathrm{Ni}=$ Jumlah individu spesies ke-i

$\mathrm{Pi} \quad=$ Perbandingan jumlah ikan ke I (ni/N)

$\mathrm{i} \quad=1,2,3,4, \ldots . \mathrm{dst}$

$\mathrm{S} \quad=$ Jumlah spesies ikan

Kriteria hasil keanekaragaman berdasarkan Shannon-Wiener : 


$$
\begin{aligned}
& H^{\prime} \leq 3,32=\text { Keanekaragaman rendah } \\
& 3,32 \leq H^{\prime} \leq 9,97=\text { Keanekaragaman sedang } \\
& H^{\prime} \geq 9,97 \quad=\text { Keanekaragaman tinggi }
\end{aligned}
$$

\section{HASIL DAN PEMBAHASAN}

\section{Hasil Penelitian}

Tabel 1. Nama Spesies dan jumlah individu yang

\begin{tabular}{|c|c|c|c|c|}
\hline Ordo & Famili & Spesies & Waktu & $\begin{array}{l}\text { Jumlah } \\
\text { Spesies }\end{array}$ \\
\hline \multirow{5}{*}{ Anura } & Bufonidae & $\begin{array}{l}\text { Kodok } \\
\text { kolong } \\
\text { (Bufo } \\
\text { melanost } \\
\text { ictus) }\end{array}$ & $\begin{array}{l}\text { Pagi dan } \\
\text { sore }\end{array}$ & 4 \\
\hline & Ranidae & $\begin{array}{l}\text { Kodok } \\
\text { sawah } \\
\text { (Fejervarya } \\
\text { cancrivo } \\
\text { ra) }\end{array}$ & pagi & 2 \\
\hline & Rhacophoridae & $\begin{array}{l}\text { Katak } \\
\text { pohon } \\
\text { (Polyped } \\
\text { ates } \\
\quad \text { leucomys } \\
\quad \text { tax) }\end{array}$ & Pagi & 2 \\
\hline & Ranidae & $\begin{array}{l}\text { Kongkang } \\
\text { Siberut } \\
\text { (Pulchranacent } \\
\text { ropeninsularis) }\end{array}$ & Pagi & 1 \\
\hline & Ranidae & $\begin{array}{l}\text { Katak panggul } \\
\text { (Limnonectes } \\
\text { blythii) }\end{array}$ & sore & 1 \\
\hline
\end{tabular}
ditemuakan di Desa Karang Rejo, Kecamatan Wih Pesam Kabupaten Bener Meriah.

Tabel 2. Indeks keanekaragaman ukuran (H') dari 1 stasiun didapatkan hasil sebagai berikut.

\begin{tabular}{lll}
\hline Family & Spesies & H' \\
\hline Bufonid ae & Bufomelanost ictus & 0,367 \\
& & \\
Ranidae & Fejervarya cancricora & 0,145 \\
Racophorid ae & Polypedates leucomys & 0,145 \\
& tax & \\
Ranidae & Pulchranac entropenins & 0,047 \\
& ularis & \\
Ranidae & Limnonect es blythii & 0,047 \\
& TOTAL & 0,4207 \\
\hline
\end{tabular}

Berdasarkan tabel diatas jumlah Ordo Anura yang di temukan di perkebunan kopi Desa Karang Rejo, Kecamatan Wiih Pesam, Kabupaten Bener Meriah. Berjumlah 4 spesies dari 3 jenis spesies diantaranya spesies Kodok kolong (Bufo melanostictus) dari family Bufonidae, Kodok Sawah (Fejervarya cancrivora) dari family Ranidae dan yang terakhir Katak pohon (Polypedates leucomystax) dari family Rhacophoridae.

Spesies pertama yang ditemukan Bufo melanostictus atau biasa disebut kodok kolong bertubuh sedikit bulat kemudian memiliki ciri yaitu terdapat garis hitam keras dari moncong diatas mata sampai gendang telinga, memiliki tekstur kulit sangat kasar serta memiliki 2 bintil hitam besar dan bintil abu-abu hitam kecil tersebar tak beraturan, ujung jari berkuku, warna punggung coklat muda dengan bintil hitam juga terdapat alur berwarna coklat tua dengan habitat dekat hunian manusia atau wilayah yang terganggu juga di hutan primer dan hutan sekunder (Huda. 2018) kodok kolong ditemukan pada lahan kebun kopi yang mendekati pemukiman warga Desa Karang rejo wajar saja karena pada dasarnya habitat asli kodok kolong ini adalah dekat hunian manusia hal itu sejalan dengan letak perkebunan kopi di Desa Karang Rejo, Kecamatan Wih Pesam, Kabupaten Bener Meriah berada di tengahtengah pemukiman warga sehingga tidak jarang 
kodok kolong ini sering ditemukan baik pada pagi dan sore hari.

\section{Spesies Ordo Anura kedua adalah} Fejervarya cancrivora atau sering disebut kodok sawah yang memiliki ciri khusus diantaranya memiliki punggung yang berwarna coklat dengan bercak berwarna hitam kemudian tekstur kulit yang licin akan tetapi terdapat bintil-bintil halus pada permukaan tubuhnya, pada bagian punggung terdapat lipatan kulit memanjang putus-putus dengan puncaknya yang berwarna hitam. Spesies ini biasa ditemukan di dekat area persawahan (Huda.2018). sejalan dengan menurut (Iskandar. 1998 dalam Huda. 2018) Fejervarya cancrivora memiliki warna punggung yang gelap, kehijauan, kemerahan dengan bercak gelap, tekstur kulit terdapat kerutan di punggung atau lipatan-lipatan memanjang paralel dengan sumbu tubuh. Selaput renang mencapai ujung kecuali 1 atau 2 ruas jari kaki keempat (yang terpanjang). Fejervarya cancrivora berhabitat di sawah- sawah, juga di tempat-tempat yang tidak jauh dari sungai, kebun dan saluran air.

Fejervarya cancrivora umumnya ditemukan di persawahan sehingga sering disebut kodok sawah namun tidak jarang pula kodok sawah ini ditemukan pada perkebunan lain seperti halnya perkebunan kopi namun spesies ini terletak pada perkebunan kopi yang lembab pada musim hujan atau pada genangan air yang sengaja dibuat oleh petani untuk penampungan air hujan. Ranidae jenis Kodok sawah ini ditemukan pada pagi hari setelah hujan semalaman sesuai habitat nya yang lembab kodok ini tidak dapat ditemukan disiang hari karena ia akan bersembunyi agar tidak tersengat sinar matahari.

$$
\text { Spesies ketiga Polypedates }
$$

leucomystax dari Familia Rhacophoridae, biasa disebut Katak pohon bergaris Spesies ini memiliki khas berpostur tubuh ramping, warna bercorak coklat, pada tungkai belakang bercorak kehitaman. Mata menonjol danterdapat lingkaran emas. Memiliki moncong yang berbentuk segitiga namun tidak terlalu runcing. Tungkai depan pendek, tidak berselaput, sedangkan tungkai belakang panjang, terdapat selaput $3 / 4$ bagian, memiliki discus dan nuptial pad. Pelvic girdle sangat menonjol. Habitat katakini banyak ditemukan di area bervegetasi rendah. Kadang juga banyak ditemukan di area pemukiman warga (Iskandar, 1998).

Katak pohon bergaris ditemukan pada pagi hari diperkebunan kopi yang masih lembab, seperti halnya kodok kolong katak ini kadang ditemukan pada area pemukiman warga yang dekat dengan perkebunan kopi.

Selanjutnya Ordo Anura selanjutnya adalah (Pulchranacentropeninsularis) atau biasa disebut Kongkang Siberut, Kongkang 
siberut memiliki morfologi tubuh berukuran sedang, kemudian mempunyai ruas jari kaki depan pertama lebih panjang dari kedua, jari keempat dan ketiga, tekstur kulit atas sedikit kasar dan bagian bawah halus, kongkang siberut memiliki warna yang sangat menarik dengan paduan bagian punggung keunguan sampai hitam, di pisahkan oleh pola warna kuning kemerahan pada sisi tubuh dari moncong hingga anal, pada sisi tubuh dan kaki terdapat bercak-bercak berwarna kekuningan, tubu bagian bawah berwarna putih keungu-unguan. Kongkang siberut biasanya memiliki Habitat Menghuni hutan sekunder tua pada sungai-sungai berukuran sedang sampai pada anak sungai berarus lemah.

Kemudian Ordo Anura yang ditemukan adalah (Limnonectes blythii) atau biasa disebut Katak panggul, Katak panggul memiliki morfologi tubuh berukuran besar, dengan moncong menyudut lancip, pada tubuhnya memiliki garis gelap, kemudian pada bagian mata kaki bagian belakang panjang dan kuat, memiliki selaput renang penuh, biasanya katak panggul memiliki habitat pada pinggiran sungai dan anakan sungai kecil kemudian saat musim berbiak jantan akan menggali pasir atau tanah berbentuk cekung, untuk betina meletakan telur.
Berdasarkan hasil perhitungan indeks Shanon-Wiener menunjukan bahwa $\mathrm{H}^{\mathrm{I}}=$ 0,4207. Angka 0,4207 menunjukan bahwa tingkat keanekaragaman ordo Anura yang terdapat di kebun kopi, Desa Karang Rejo Kabupaten Bener Meriah adalah rendah.

Karakter fisik seperti suhu udara, air dan kelembapan, pH tanah pada lokasi penelitian juga mempengaruhi kehidupan Amfibi.

\section{KESIMPULAN}

Pada pengamatan yang telah dilakukan di kebun kopi desa Karan rejo ditemukan 5 jenis spesies. Spesies pertama yang ditemukan Bufo melanostictus atau biasa disebut kodok kolong jenis spesies ini adalah jenis yang paling banyak ditemukan pada lahan kebun kopi yang mendekati pemukiman warga Desa Karang rejo, wajar saja karena pada dasarnya habitat asli kodok kolong ini adalah dekat hunian manusia hal itu sejalan dengan letak perkebunan kopi di Desa Karang Rejo, Kecamatan Wih Pesam, Kabupaten Bener Meriah berada di tengah-tengah pemukiman warga sehingga tidak jarang kodok kolong ini sering ditemukan baik pada pagi dan sore hari.

Spesies Ordo Anura kedua adalah Fejervarya cancrivora atau sering disebut kodok sawah yang memiliki ciri khusus diantaranya memiliki punggung yang berwarna coklat dengan bercak berwarna 
hitam kemudian tekstur kulit yang licin akan tetapi terdapat bintil-bintil halus pada permukaan tubuhnya, pada bagian punggung terdapat lipatan kulit memanjang putus-putus dengan puncaknya yang berwarna hitam.

Jenis spesies yang ke tiga adalah Fejervarya cancrivora, umumnya ditemukan di persawahan sehingga sering disebut kodok sawah namun tidak jarang pula kodok sawah ini ditemukan pada perkebunan lain seperti halnya perkebunan kopi namun spesies ini terletak pada perkebunan kopi yang lembab pada musim hujan atau pada genangan air yang sengaja dibuat oleh petani untuk penampungan air hujan.

Kemudian jenis spesies
(Pulchranacentropeninsularis) atau biasa disebut Kongkang Siberut, jenis kongkang siberut ini adalah Spesies dari Ordo Anura yang paling menarik dibandingkan yang lain. Dan spesies terakhir yang ditemukan adalah (Limnonectes blythii) atau biasa disebut Katak panggul, katak ini berbeda dari katak pada umumnya karena berbadan besar biasanya hidup di perairan.

Keanekaragaman Amfibi Ordo Anura yang terdapat di kebun kopi, Desa Karang Rejo Kabupaten Bener Meriah adalah rendah yaitu 0,4207 .

\section{DAFTAR PUSTAKA}

Dharma, A.P. \& Meitiyani. (2019). Inventarisasi Amfibi Resort Cisarua Taman Nasional Gunung Gede Pangrangoberdasarkan musim yang berbeda. Biosilampari, 2(1), 1-5. DOI. DOI:10.31540/biosilampari.v2i1.585.

Eprilurahman, R., \& Kusuma, K. I. (2011). Amfibi dan Reptil di lereng selatan gunungapi Merapi sebelum erupsi 2010. Berkala Ilmiah Biologi-A Scientific Periodical, 10(1), 1-8.

Heyer WR, Donelly MA, McDiamid RW, Hayek L.AC, dan MS Foster. 1994. Measuring and monitoring biological diversity. Standard methods for amphibians. Washington (US): Smithsonian Institution Press.

Huda, N. (2018). Inventarisasi Keanekaragaman Amfibi di Kawasan Wisata Air Terjun Bajuin Kabupaten Tanah Laut. Jurnal Pendidikan Hayati, 4(2), 85-92.

Irwanto, R., Lingga, R., Pratama, R., \& Ifafah, S. A (2019). Identifikasi jenisjenis Herpetofauna di Taman Wisata Alam Gunung Permisan, Bangka Selatan, Provinsi Kepulauan Bangka Belitung. PENDIPA Journal of Science Education, 3(2), 106113. https://doi.org/10.33369/pendipa.v3i $\underline{2.7707}$

Iskandar, D.T., 1998. Amfibi Jawa dan Bali: Seri Panduan Lapangan. Cetakan pertama, Puslitbang Biologi-LIPI, Bogor. Hal : $1-7$.

Kusrini, M. D. (2013). Panduan Bergambar Identifikasi Amfibi Jawa Barat. Bogor: Fakultas Kehutanan IPB dan Direktorat Konservasi Keanekaragaman Hayati.

Mistar.(2003). Panduan Lapangan Amfibi Kawasan Ekosistem Leuser. The Gibbon Foundation dan PILI-NGO Movement. Bogor Sardi, M., Erianto, danSiahaan, S. 2012. 
Keanekaragaman herpetofauna di Resort Lekawai Kawasan Taman Nasional Bukit Baka Bukit Raya Kabupaten Sintang Kalimantan Barat. Jurnal Hutan Lestari.vol 2(1):126-133.

Subeno. 2018. Distribusi dan keanekaragaman herpetofauna di Hulu Sungai Gunung Sindoro, Jawa Tengah. Jurnal Ilmu Kehutanan. vol 12(1):40-51.doi:

https://doi.org/10.22146/jik.34108

Zug, G. R. (1993). \& Caldwell (2014) Herpetology: An Introduction Biology of Amphibisns and Reptiles.NewYork: Academic Pres 